toring the site afterwards.

The proposed rules are expected to keep a close watch on transgenic plants being developed for the production of therapeutic agents and immunologically reactive proteins. In one proposed field test in Oklahoma, for example, alfalfa plants with part of the cholera toxin gene would be tested for their ability to produce large amounts of biologically active peptide or protein used in the development of a vaccine.

Terry Medley, chief of USDA's biotechnology section, says that not enough is known about the interaction of genetically engineered crops with their environment to remove other regulations, but that the proposed changes should both help to allay public fears about the technology and maintain the competitiveness of new exports.

But some academics call Medley a government bureaucrat who is "bullying" the rules through the system to protect his regulatory turf. Suzanne Huttner, director of the Systemwide Biotechnology Program at the University of California, says the changes do not go far enough and that researchers working on the six crops should be permitted to notify US agriculture officials the day they plant. She would also like to exempt researchers from the need for a permit on new plants or other organisms not previously identified as plant pests.

In a letter to the White House Council on Competitiveness, Huttner and other university researchers asked for the removal of all special rules for biotechnology field tests. Huttner says that USDA rules add to the cost of research and to public fears of the technology by focusing on the process of genetic engineering. The proposal "definitely sells out basic research", Huttner says. "It guarantees that these products will sit on laboratory shelves and never see the light of day."

But environmentalists and industry, usually on opposite sides of regulatory questions, have joined to support the USDA proposal. The Industrial Biotechnology Association believes that continued federal review will help it to win public acceptance and stave off more restrictive state actions. North Carolina, Minnesota and West Virginia, for example, have enacted their own rules covering environmental release of genetically engineered organisms. "We believe [the USDA proposal] is a sound step and scientifically justified," says Alan Goldhammer, director of technical affairs for the US trade group. US companies should be able to notify USDA for most of their field tests, he predicts.

At the same time, environmental groups are now concerned that USDA may abandon its cautious approach to regulating genetically engineered plants and choose same-day notification, which would prevent environmentalists or states from commenting on field tests before they begin or replace a detailed list of exemptions with a broader rule.

Sally Lehrman

\title{
Nobel Prizes go to Caltech chemist, CERN physicist
}

\section{Physics prize}

London. This year's Nobel Prize in physics has been awarded to a man whose inventions have formed the basis of high-energy particle detection for the past twenty years. Georges Charpak, 68, who has spent most of his career at CERN, the European Laboratory for Particle Physics, is cited in particular for the invention, in 1968, of the multiwire proportional chamber - a device whose descendants are active in most high-energy IMAGE physics experiUNAVAILABLE ments operating FOR COPYRIGHT REASONS

From the earliest days of nuclear physics, the identification and study of subatomic particles has relied on ways of making visible the trail of ioni-

\section{Georges Charpak} zation created by an energetic particle as it
travels through matter. Wilson's cloud chamber, Powell's high-quality photographic emulsions and Glaser's bubble chamber all Nobel-prize-winning inventions revealed a host of new particles from cosmic rays and accelerators, starting with the discovery of the positron in 1932 .

But as physicists started to look for rarer particles, they needed an automated way to find exotic tracks among millions of more common events. They also needed speed: at only about one 'snapshot' per second, the bubble chamber could not keep up with increasingly intense accelerator beams.

Charpak's contribution was to see how to combine high spatial resolution with the speed and output offered by existing electronic detection methods. He returned to a device that had been used as early as 1908 by Rutherford and Geiger: the proportional counter, a gas-filled tube with a thin, highvoltage wire at its centre. The passage of an energetic particle ionizes the gas, triggering a pulse of electrons onto the wire. Charpak realized that an array of such wires, spaced 1-2 millimetres apart in a gas-filled chamber, would act as independent sensors and could thus be used to track a particle's path. The electrical pulses could be sent directly to a computer, with a detection rate as high as a million particles per second per wire.

In their 1968 paper, Charpak et al. also proposed an important refinement of the technique: measurement of the 'drift' time between the initial ionization of the gas and the arrival of the electron pulse at the wire, to provide even better spatial resolution. But
Charpak has lately turned away from particle physics to apply his detectors to biology and medicine. His spherical drift chamber is a highly efficient detector for the X-ray determination of protein structures, and his imaging proportional chambers bring far greater sensitivity than photographic film to the autoradiography of biological samples.

Laura Garwin

\section{Chemistry prize}

Pasadena. A theoretical chemist at the California Institute of Technology has won the 1992 Nobel Prize in chemistry for his contributions to the theory of electron-transfer reactions. Rudolph Marcus, 69, received the prize for a series of papers, published between 1956 and 1965, that explained puzzling variations in reaction rates in redox processes and made counterintuitive predictions not verified experimentally until the 1980s.

One of Marcus's first contributions was to elucidate the role of surrounding solvent molecules in determining the rate of redox reactions IMAGE - reactions that are fundamental UNAVAILABLE in energy storage, transport and conversion. Marcus FOR COPYRIGHT further determined that the relationREASONS

between the driving force of an electron-transfer reaction and the reaction's rate is described by a parabola. This im-

Rudolph Marcus plies that as more driving force is applied to
a reaction, its rate at first increases but then begins to decrease in the so-called inverted region. Chemists greeted this surprising insight with considerable scepticism until its experimental verification in 1985 .

Although the royal Swedish Academy of Sciences cited only Marcus's electron transfer work, he has made contributions in several other areas. For example, his name is the $\mathbf{M}$ in RRKM theory (the others are Rice, Ramsperger and Kassel), an attempt to explain unimolecular reactions that has found wide application in chemical physics. $\mathrm{He}$ has also done important work in transitionstate theory and in the theory of collisions and bound states. Marcus has continued his research in electron transfer, more recently turning his attention from simple reactions to reactions in complex molecules such as the proteins involved in photosynthesis.

Robert Finn 